\section{Essential function of Wnt-4 in mammary gland development downstream of progesterone signaling}

\author{
Cathrin Brisken, ${ }^{1}$ Anna Heineman, ${ }^{1}$ \\ Tony Chavarria, ${ }^{1}$ Brian Elenbaas, ${ }^{1}$ Jian Tan, ${ }^{2}$ \\ Sudhansu K. Dey, ${ }^{2}$ Jill A. McMahon, ${ }^{3}$ \\ Andrew P. McMahon, ${ }^{3}$ and Robert A. Weinberg ${ }^{1,4}$ \\ ${ }^{1}$ Department of Molecular and Integrative Physiology, \\ Whitehead Institute, Cambridge, Massachusetts 02142 USA; \\ ${ }^{2}$ University of Kansas Medical Center, Kansas City, Kansas \\ 66160 USA; $^{3}$ Department of Molecular and Cellular Biology, \\ The BioLabs, Harvard University, Cambridge, \\ Massachusetts 02138 USA
}

Female reproductive hormones control mammary gland morphogenesis. In the absence of the progesterone receptor (PR) from the mammary epithelium, ductal sidebranching fails to occur. We can overcome this defect by ectopic expression of the protooncogene Wnt-1. Transplantation of mammary epithelia from $W n t-4^{-} /^{-}$mice shows that Wnt-4 has an essential role in side-branching early in pregnancy. $P R$ and $W n t-4 \mathrm{mRNAs}$ colocalize to the luminal compartment of the ductal epithelium. Progesterone induces Wnt-4 in mammary epithelial cells and is required for increased $W n t-4$ expression during pregnancy. Thus, Wnt signaling is essential in mediating progesterone function during mammary gland morphogenesis.

Received January 11, 2000; revised version accepted February 9, 2000.

Development of the mammary gland occurs largely postnatally under the control of the female reproductive hormones estrogen, progesterone, and prolactin (Nandi 1958). A system of ducts grows outward from the nipple into the mammary fat pad that lies under the skin. The ducts then elongate and bifurcate during puberty until they reach the edges of the fat pad (Daniel and Silberstein 1987). Subsequently, with recurrent estrous cycles and during early pregnancy the ductal system increases in complexity through the addition of sidebranches that sprout from the preexisting ducts (Daniel and Silberstein 1987). The mechanisms that enable the systemic factors to control locally acting factors involved in these morphogenetic events remain largely unknown. Recently, we and others have shown that progesterone acts via the progesterone receptor (PR) in the mammary epithelium to induce side-branching (Lydon et al. 1995; Humphreys

[Key Words: Mammary gland; morphogenesis; Wnt-4 signaling; sidebranching, progesterone function]

${ }^{4}$ Corresponding author.

E-MAIL weinberg@mit.edu; FAX (617) 258-5213. et al. 1997; Brisken et al. 1998) and that it does so by a paracrine mechanism (Brisken et al. 1998).

We speculated that Wnt proteins might function as the paracrine factors that operate downstream of progesterone and the PR to mediate the process of side-branching. Wnt proteins have important roles in the development of various vertebrate and invertebrate tissues (Nusse and Varmus 1992; Cadigan and Nusse 1997). These factors are secreted glycoproteins that bind to members of the Frizzled family of seven-transmembrane-domain receptors. Several Wnt genes can function as oncogenes in the mouse breast when their transcription is activated by insertion of the provirus mouse mammary tumor virus (MMTV) (Nusse and Varmus 1982; Roelink et al. 1990; Lee et al. 1995) or when they are expressed ectopically (Tsukamoto et al. 1988).

\section{Results and Discussion}

To test whether a Wnt factor might function downstream of progesterone signaling in triggering ductal side-branching in the breast, we crossed mice carrying an MMTV LTR-driven Wnt-1 transgene (Tsukamoto et al. 1988) with mice heterozygous for a previously described inactivating mutation at the $P R$ locus (Lydon et al. 1995), to generate $W n t-1$ transgenic females that were either $P R^{-/-}$or $P R^{+/+}$. We then sought to test whether the ectopically expressed Wnt-1 protein might restore the sidebranching that is lacking in $P R^{-/-}$mammary ducts (Fig. 1A).

Mammary epithelia were removed from mice of both genotypes and transplanted into the inguinal fat pads of 3 -week-old $\mathrm{PR}^{+/+}$females. These fat pads previously had been surgically cleared of endogenous epithelium. When epithelial tissue (DeOme et al. 1959) or primary cells (Daniel and DeOme 1965) are engrafted into such cleared fat pads, they are able to form a new ductal system. These recipient females were also mutant at the RAG1 locus $\left(R A G 1^{-/-}\right)$, as these mice are immunocompromised and therefore able to accept allografts (Mombaerts et al. 1992; Brisken et al. 1998).

Ten weeks after grafting, control unmanipulated mammary glands in these recipient females showed a simple ductal system characteristic of a 13-week-old virgin mouse. However, the fat pads carrying implanted $P R^{+/+}$. MMTV $W n t-1^{t g}$ and $P R^{-/-}$MMTV Wnt- $1^{t g}$ epithelia showed increased side-branching (Fig. 1B). Thus, ectopic expression of Wnt-1 can induce side-branching in a $P R^{-/-}$epithelium in which side-branching is defective, suggesting that Wnt signaling can mimic this progesterone-induced response and may therefore act downstream of the PR.

We reported previously that in chimeric epithelia derived from mixed wild-type and $P R^{-/-}$mammary epithelial cells (MECs), the branching defect of the mutant MECs could be rescued if these cells grew in close proximity to their wild-type counterparts (Brisken et al. 1998). This suggests that progesterone elicits its morpho- 

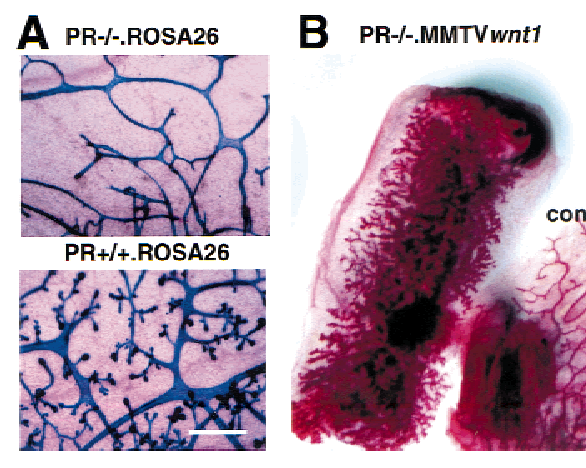

PR+/+.MMTVwnt1

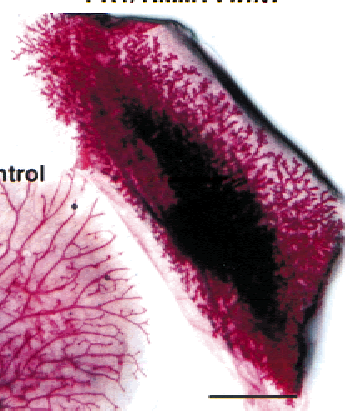

Figure 1. Side-branching in the presence of Wnt-1 and absence of the PR. (A) Intrinsic side-branching defect in $P R^{-/-}$mammary epithelium. Mammary epithelium was harvested from $P R^{-/-} R O S A 26$ (top) and $P R^{+/+}$ROSA26 (bottom) 10-week-old female mice and engrafted to the cleared fat pads of 3-week-old $\mathrm{F}_{1}$ (129SV/C57B16) recipients. Shown are whole-mount preparations of mammary glands subjected to X-gal stain, from a recipient at day 12 of pregnancy ( 10 weeks after surgery). Results were similar to those reported previously. Bar, 400, $\mu \mathrm{m}$. (B) Constitutive side-branching of MMTV Wnt-1 ${ }^{\text {tg }}$ irrespective of the PR status. Mammary epithelium was harvested from $P R^{-/-}$MMTV $W n t-1^{t g}$ and $P R^{+/+} M M T V W n t-1^{t b} 10$-week-old female mice and engrafted to the cleared fat pads of 3 -week-old recipients. Shown are whole-mount preparations of mammary gland from a virgin $\mathrm{RAG}^{-/-}$recipient 10 weeks after surgery. (Left) Inguinal fat pad engrafted with $P R^{-/-}$MMTV Wnt $-1^{\text {tg }}$ mammary epithelium; (right) inguinal fat pad engrafted with $P R^{+/+}$MMTV Wnt-1 $1^{t g}$ mammary epithelium; (center) thoracic mammary gland, as an ungrafted endogenous control. Identical results were obtained in 16 independent grafts of $P R^{-/-}$MMTV Wnt- $1^{t g}$ and control mammary epithelium. Bar, $5 \mathrm{~mm}$.

genetic effects, at least in part, by causing PR-positive MECs to release a factor that acts over short distances on other cells within the breast.

To test whether Wnt-1 also acts in a paracrine fashion to induce side-branching, we mixed MMTV Wnt- $1^{\text {tg }}$ MECs with MECs derived from ROSA26 mice (Friedrich and Soriano 1993). These latter cells carry a lacZ transgene, which makes their identification possible upon whole mount analysis of breast tissue. As expected, the MMTV Wnt-1 ${ }^{\text {tg }}$ cells, stained in red, showed increased side-branching (Fig. 2). In addition, the blue wild-type cells carrying the lac $Z$ transgene, located adjacent to these MMTV Wnt-1 ${ }^{t g}$ MECs, also showed increased sidebranching. This indicates that secreted Wnt-1 is sufficient to cause side-branching and that Wnt-1, like the factor released by PR-positive cells, acts in a paracrine fashion to induce side-branching. When wild-type MECs were mixed with MECs derived from ROSA26 mice, ductal branching was not affected (data not shown), indicating that the increased branching is not induced by experimental manipulation.

Although these experiments indicate that a Wnt protein was sufficient for side-branching, being able to mimic the morphogenetic response normally elicited by progesterone, they did not resolve whether a Wnt factor has an essential role in the normal morphogenetic process. Wnt-1 itself is not normally expressed in the mammary gland, but the related gene Wnt-4 (Munsterberg et al. 1995; Kispert et al. 1998), which acts similarly to
Wnt-1 when ectopically expressed in the mammary epithelium (Bradbury et al. 1995), is expressed during the period when side-branching occurs in early to mid-pregnancy (Gavin and McMahon 1992; WeberHall et al. 1994). To evaluate the specific role of Wnt-4 in mammary morphogenesis, we analyzed mammary epithelium from mice lacking both copies of the Wnt-4 gene (Stark et al. 1994). These mice die perinatally due to kidney failure (Stark et al. 1994), precluding analysis of subsequent mammary development. Responding to this, we harvested the mammary buds from 14.5-day-old Wnt-4-1- and wild-type embryos and engrafted them into the cleared mammary fat pads of wild-type hosts. Both types of implants initially gave rise to normal ductal systems in virgin recipients (Fig. 3, left). However, at day 12 of pregnancy Wnt-4-1- implants showed substantially less ductal branching than their wild-type counterparts (Fig. 3, middle). Later in pregnancy, engrafted $W n t-4^{-1-}$ epithelia began to resemble wild-type epithelial grafts, exhibiting a more normal pattern of arborization (Fig. 3, right). This may be explained by the actions of other members of the Wnt family of factors that are known to be expressed late in pregnancy, such as Wnt-5a, Wnt-5b, and Wnt-6.

In situ hybridization with $P R$ - and Wnt-4-specific cRNA probes on sections of mammary glands from virgin mice and during early pregnancy (days 4 and 8) reveal that both molecules are expressed at low levels in the virgin and induced during pregnancy (Fig. 4, top). Higher magnifications illustrate that as reported

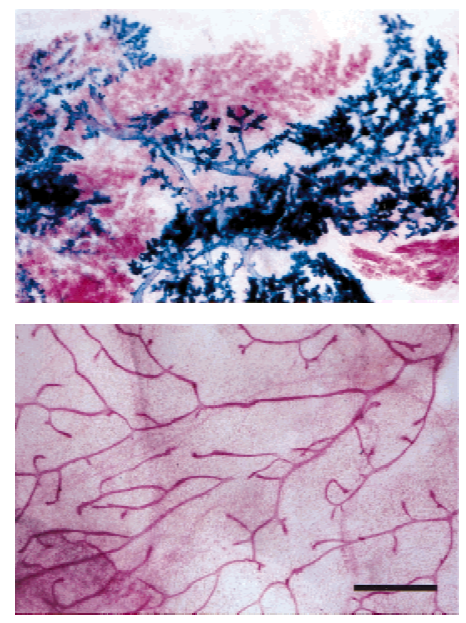

Figure 2. Paracrine induction of side-branching by Wnt-1. Primary mammary epithelial cells were derived from 10-week-old MMTV Wnt- $1^{\text {tg }}$ and ROSA26 females. After 5 days in vitro culture, the cells were trypsinized, mixed in a 1:1 ratio, and injected into cleared fat pads of 3-week-old $R A G 1^{-/-}$recipients. Mammary glands from $R A G 1^{-/-}$recipients at 10 weeks after surgery were subjected to X-gal stain, carmine alum counterstain, and mounted whole. (Top) Cleared fat pad reconstituted with a mixture of ROSA26 (blue) and MMTV Wnt1 (red) mammary epithelial cells; (bottom) ungrafted control, thoracic mammary gland. Bar, $500 \mu \mathrm{m}$. Wnt-1 overexpressing cells (red) induce premature side-branching in wild-type cells (blue). 


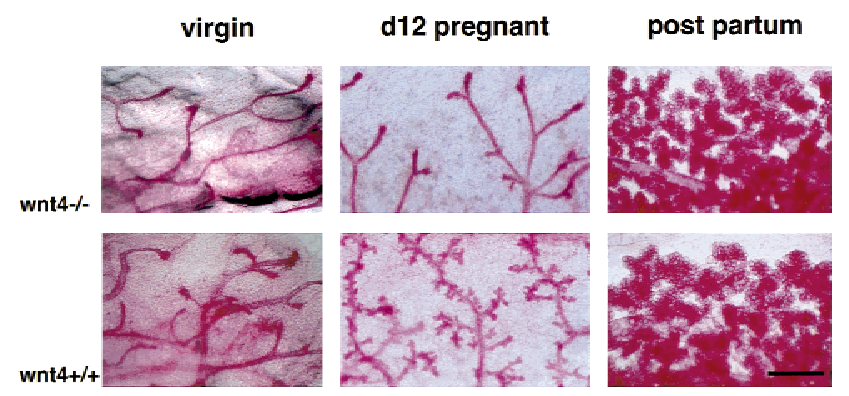

Figure 3. Function of Wnt-4 in the mammary epithelium at mid-pregnancy. Mammary buds were prepared from $\mathrm{Wnt}-\mathrm{4}^{-/-}$ and wild-type littermates (129SV/C57B16 mixed genetic background) at E14.5 and engrafted to the cleared fat pads of 3-weekold $F_{1}(129 S V / C 57 B 16)$ recipients. At 10 weeks after surgery the mammary glands from virgin and impregnated recipients were analyzed by whole-mount preparation. (Top) Mutant grafts; (bottom) wild-type control grafts. Shown are mammary glands derived from a grafted virgin mouse (left), a mouse at day 12 of pregnancy (center), or at parturition (right). Wnt-4-/- epithelium fails to initiate side-branching at day 12 of pregnancy. Results were obtained with 4 virgin, 10 mid-pregnant, and 5 recipients at parturition. Bar $500 \mu \mathrm{m}$.

previously (Silberstein et al. 1996), the PR is not expressed in the myoepithelium but is restricted instead to the luminal epithelium (see arrows in Fig. 4, bottom) and that the same is true for Wnt-4. The same colocalization was observed on sections from the murine uterus during early pregnancy (data not shown). These observations of colocalized expression are consistent with a model that progesterone signaling induces Wnt-4 expression.

To test whether Wnt-4 expression is under the control of progesterone, we injected groups of ovariectomized mice with either 17$\beta$-estradiol, 17- $\beta$-estradiol and progesterone, or the vehicle alone for 20 days as described (Said et al. 1997). 17- $\beta$-Estradiol injections were required to induce expression of the PR in MECs (Said et al. 1997). At the end of these treatments, one mammary gland from each mouse was analyzed by whole-mount microscopy to assess the morphology of the ductal system, enabling us to control for adequate gonadectomy in the vehicle-treated mice and to assess the efficacy of hormone replacement in the stimulated mice. RNA was extracted from a second mammary gland of each mouse and assayed by RT-PCR for levels of GAPDH and Wnt-4 mRNA expression. We found a slight increase in the expression of Wnt-4 mRNA in response to $17-\beta$-estradiol treatment alone, but a three- to fivefold increase of Wnt-4 mRNA following 17- $\beta$-estradiol and progesterone treatment (Fig. 5A).

The above results suggest that increased Wnt-4 expression during pregnancy is under progesterone control. To test this possibility further, we assayed Wnt-4 expression in the mammary glands of pregnant mice that had been engrafted with $P R^{-/-}$epithelium in one fat pad and $\mathrm{PR}^{+/+}$epithelium in the contralateral fat pad. In both cases, the transplanted epithelial cells also carried a lac $Z$ gene, enabling us to use RT-PCR analysis to gauge the level of RNA recovered from the engrafted epithelium of each reconstituted gland. At day 12 of pregnancy, a threefold difference between the levels of Wnt-4 mRNA was consistently observed between the $P R^{-/-}$implants and their wild-type counterparts (Fig. 5B), which compares to the induction of endogenous Wnt-4 expression normally seen during pregnancy (Gavin and McMahon 1992; Weber-Hall et al. 1994; data not shown). The levels of lacZ mRNA were comparable between the two grafts. Thus, progesterone signaling is required within the grafted mammary epithelium for the induction of Wnt-4 expression that is normally seen during pregnancy.

To test whether the induction of Wnt-4 by progesterone is a direct effect of PR action on mammary epithelial cells, we treated primary MECs in culture with progesterone. As shown in Figure 5C, representative of eight independent experiments, Wnt-4 RNA expression was significantly induced as early as $4-8 \mathrm{hr}$ after progesterone

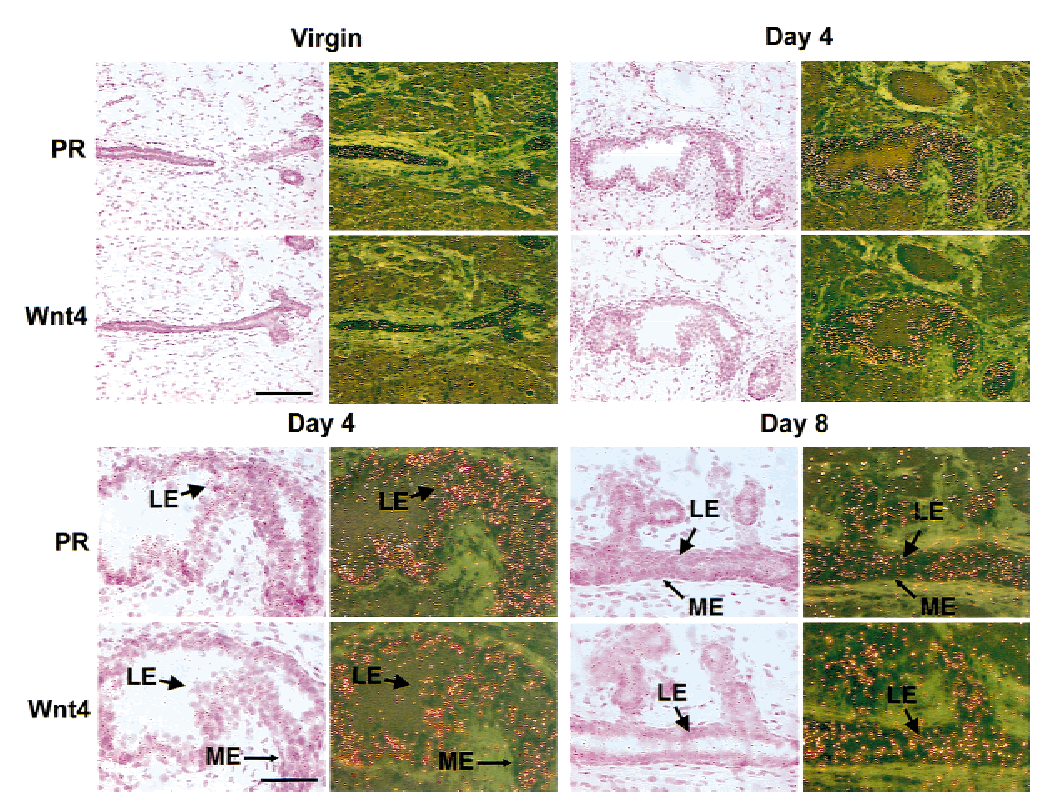

Figure 4. Coexpression of $P R$ and Wnt-4 mRNAs in the luminal mammary epithelium. Mammary glands were harvested from a virgin adult female mouse and from mice at days 4 and 8 of pregnancy. The glands were processed for in situ hybridization; adjacent sections were hybridized with ${ }^{35}$ S-labeled antisense cRNA probes for PR or Wnt-4 and exposed for 7 days. Hematoxylin- and eosinstained sections are shown next to the corresponding dark-field exposures. (Top) Coordinated induction of $P R$ and Wnt-4 mRNAs during pregnancy. Low magnification (bar, $150 \mu \mathrm{m}$ ) of mammary gland showing increased signal intensity for both $P R$ and Wnt-4 mRNAs in the ductal epithelium at 4 days of pregnancy vs. virgin. (Bottom) Colocalization of $P R$ and Wnt-4 mRNA expression in the mammary luminal epithelium. High magnification (bar, $75 \mu \mathrm{m}$ ) of selections from mammary glands at days 4 and 8 of pregnancy showing that both $P R$ and Wnt-4 mRNA expression localizes to the luminal epithelium (LE) and is absent from the myoepithelium (ME). Light green areas represent the dense fibrous stroma surrounding the mammary ducts. 

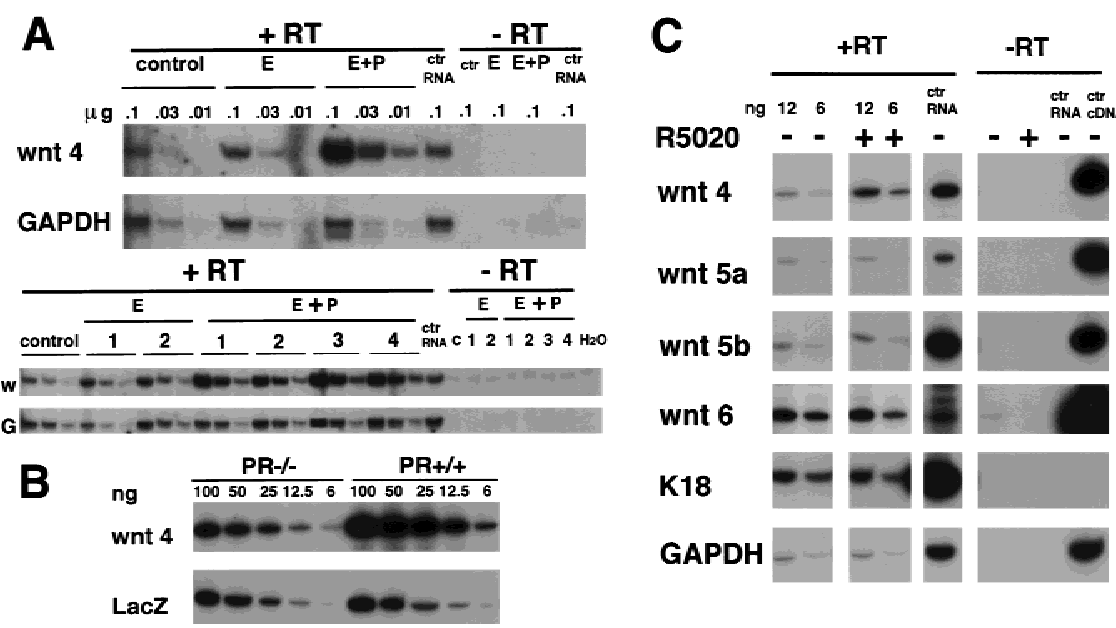

Figure 5. Induction of Wnt-4 expression in the mammary epithelium in vivo and in vitro by progesterone. (B) Quantification of Wnt-4 mRNA expression by semiquantitative PCR in mammary glands after 20 days of hormone treatment. Ten week-old virgin mice were ovarectomized. After 3 weeks they were injected for 20 days either with vehicle only (control), $10 \mu \mathrm{g}$ of 17- $\beta$-estradiol (E)/day or $10 \mu \mathrm{g}$ of estradiol and $100 \mu \mathrm{g}$ of progesterone $(\mathrm{E}+\mathrm{P}) /$ day. Total RNA was prepared from individual mammary glands, and samples in three serial dilutions, to ensure a linear signal response, were subjected to RT-PCR with primers specific for Wnt-4 or GAPDH. The same amounts of RNA in three serial dilutions were analyzed in each case. The undiluted RNA subjected to PCR amplification yielded no signal. Shown are two independent experiments, one comprising three mice (top) and one comprising seven mice (bottom). The products were quantified by densitometric scanning. The ratio of Wnt-4/GAPDH of the progesteronetreated samples was three- to fivefold higher than the 17- $\beta$-estradiol-treated samples. $(B)$ Wnt-4 mRNA expression in mammary glands engrafted with $P R^{-/-}$or $P R^{+/+}$mammary epithelium. Mammary epithelium was harvested from $P R^{-/-} R O S A 26$ and $P R^{+/+}$ ROSA26 10-week-old female mice and engrafted to the cleared fat pads of 3-week-old $\mathrm{F}_{1}$ (129SV/C57B16) recipients. Six weeks after surgery the recipients were mated and the engrafted mammary glands were harvested at day 12 of pregnancy. RNA samples in five serial dilutions were subjected to RT-PCR with primers specific for Wnt-4 as in A. In parallel, RT-PCR was performed with lacZ-specific primers allowing normalization of the amount of transplanted epithelium. Densitometry reveals that the Wnt-4 signal is increased threefold in the $P R^{-/-}$ROSA26 vs. the $P R^{+/+}$ROSA26 transplant. The same results were obtained in three independent experiments. (C) Wnt-4 mRNA expression in cultured primary mammary epithelial cells after progesterone exposure. Primary mammary epithelial cells were cultured on collagen-coated dishes for 3 days. RNA was harvested from untreated cells and cells after $8 \mathrm{hr}$ of stimulation with the progesterone agonist R5020 (20 nM) (P). Shown are two out of five serial dilutions of RNA subjected to RT-PCR with primers specific for Wnt-4, Wnt-5a, Wnt-6, keratin-18, and GAPDH. In each case, the undiluted RNA subjected to PCR ampliification without reverse transcription yielded no signal. Although the levels of Wnt-5a, Wnt-5b, Wnt-6, keratin-18, and GAPDH mRNA were unaffected by the treatment with R5020, the levels of Wnt-4 mRNA increased two- to threefold within 4-8 hours as confirmed in eight independent experiments.

exposure. However, the expression levels of Wnt-5a, Wnt-5b, and Wnt-6, which are also increased during pregnancy, were unaffected by progesterone treatment. Further studies to determine whether Wnt-4 induction by progesterone could occur in the presence of the protein synthesis inhibitor cycloheximide, were hampered by increased basal Wnt-4 mRNA levels induced by the cycloheximide treatment, possibly reflecting cycloheximide-induced stabilization of Wnt-4 mRNA /data not shown).

Together, our findings indicate that Wnt signaling is centrally important to progesterone-induced side- branching of the mammary ductal epithelium. In contrast, a second major morphogenetic process in the mammary gland-ductal elongation-does not appear to be mediated by Wnt signaling. In support of this, the work of others has demonstrated that the defect in ductal elongation observed in epithelia lacking the estrogen receptor is not reversed in the presence of the MMTV-driven Wnt-1 transgene (Lubahn et al. 1993; Bocchinfuso et al. 1999).

Although we find that Wnt-4 is the only Wnt gene directly induced by progesterone, it is not unique in its ability to trigger side-branching, as late in pregnancy, the ductal epithelium of Wnt-4-1- shows normal sidebranching. We speculate that this compensation is due to the expression of other Wnt proteins later in pregnancy (Gavin and McMahon 1992; Weber-Hall et al. 1994), consistent with the notion that various Wnt proteins trigger similar biochemical responses and that their different biological functions are due to differences in their patterns of expression.

\section{Materials and methods \\ Mice \\ ROSA26, RAG1 ${ }^{-/-}, \mathrm{Wnt}-4^{+/-}$, and $\mathrm{PR}^{+/-}$-mice were maintained on a C57Bl/6 6129 SV back- ground. Genotyping for the $\beta$-galactosidase transgene was tested by X-gal-staining tail biop- sies, PR, and MMTV Wnt-1 ${ }^{\text {tg }}$ genotyping as de- scribed (Lydon et al. 1995; Bocchinfuso et al.} 1999).

\section{Mammary glands}

E14.5 embryos were harvested from crosses of Wnt $-4^{+/-}$parents and phenotyped. The phenotyping was subsequently confirmed by PCRbased genotyping (Stark et al. 1994). The mammary anlagen were dissected and subsequently engrafted to cleared inguinal fat pads of 3-weekold recipients.

Mammary gland whole mounts, X-gal stain, and cell culture are as described previously (Brisken et al. 1998). For progesterone stimulation cells were plated on collagen-coated dishes and maintained in DMEM/F12 with prolactin $(5 \mu \mathrm{g} / \mathrm{ml})$ and insulin $(5 \mu \mathrm{g} / \mathrm{ml})$ for 3 days prior to treatment with 20 nmoles of R5020.

\section{$R T-P C R$}

Total RNA (1 $\mu \mathrm{g})$ was reverse transcribed (GIBCO BRL) using random hexamers (Boehringer). Amplification was carried out by touchdown PCR using the following primers: mouse GAPDH (Clontech), 20 cycles; lacZ (Bjornson et al. 1999), 27 cycles; keratin-18 (Schroeder and Lee 1998), 20 cycles, Wnt-4F, AGGAGTGCCAATACCAGTTCC; Wnt $4 R$; TGTGAGAAGGCTACGCCATA, 27 cycles; Wnt-5aF, ACAGGCATCAAGGAATGCCAGTA; Wnt-5aR, AACGGGTGACCATAGTCGATGT, 25 cycles; Wnt-5bF, CAGAGAGTGCCAACACCAGTTT; Wnt-5bR, TACTCCACGTTGTCTCCACA, 22 cycles; Wnt-6F, CTAG- 
GATGGTCGTAGACGTCCT, Wnt-6R, CGTTTGTGCTTTCGACAGAG; 30 cycles.

\section{In situ hybridization}

In situ hybridization was performed as described previously (Das et al. 1994). In brief, frozen sections (14 um) were mounted onto poly-L-lysinecoated slides and fixed in $4 \%$ paraformaldehyde in PBS for $15 \mathrm{~min}$ at $4^{\circ} \mathrm{C}$. The sections were prehybridized followed by hybridization with ${ }^{35} \mathrm{~S}$-labeled antisense or sense cRNA probes for Wnt4 (Stark et al. 1994) or PR (Tan et al. 1999) for $4 \mathrm{hr}$ at $45^{\circ} \mathrm{C}$. After hybridization and washing, the sections were incubated with RNase A $(20 \mu \mathrm{g} / \mathrm{ml})$ at $37^{\circ} \mathrm{C}$ for $20 \mathrm{~min}$. RNase-A-resistant hybrids were detected by autoradiography using Kodak NTB-2 liquid emulsion (Eastman Kodak, Rochester, NY). The autoradiographic exposures were from 7 to 12 days. The slides were poststained with hematoxylin and eosin. The reddish brown grains indicate the sites of mRNA accumulation. This color is the result of lateral light scattering from the eosin staining under dark-field microscopy. Day 8 uterine sections hybridized with the Wnt- 4 or $P R$ antisense probe served as positive controls, whereas sections hybridized with the sense probes served as negative controls (data not shown).

\section{Acknowledgments}

We thank K. Kratochwil, M. Planas-Silva, and Y. Sun for advice, G.P. Dotto and S. Dessain for critical reading of the manuscript, J. Lydon and B. O'Malley for providing the PR mutant animals, and H.E. Varmus for providing the MMTV Wnt- $1^{\text {tg }}$ mice. This work was supported by grants from the Department of the Army, Breast Cancer Research Program (DAMD17-96-1-6285), the NIH (NCI grant OIG R35CA3 9826); S.K.D. was supported by NIH grant R37HD12304. C.B. was a fellow of the Dr Mildred-Scheel foundation.

The publication costs of this article were defrayed in part by payment of page charges. This article must therefore be hereby marked "advertisement" in accordance with 18 USC section 1734 solely to indicate this fact.

\section{References}

Bjornson, C., R. Rietze, B. Reynolds, M. Magli, and A. Vescovi. 1999 Turning brain into blood: A hematopoietic fate adopted by adult neural stem cells in vivo. Science 283: 534-537.

Bocchinfuso, W., W. Hively, J. Couse, H. Varmus, and K. Korach. 1999. A mouse mammary tumor virus-Wnt-1 transgene induces mammary gland hyperplasia and tumorigenesis in mice lacking estrogen receptor-alpha. Cancer Res. 59: 1869-1876.

Bradbury, J.M., P.A. Edwards, C.C. Niemeyer, and T.C. Dale. 1995 Wnt-4 expression induces a pregnancy-like growth pattern in reconstituted mammary glands in virgin mice. Dev. Biol. 170: 553-563.

Brisken, C., S. Park, T. Vass, J. Lydon, B. O'Malley, and R. Weinberg. 1998. A paracrine role for the epithelial progesterone receptor in mammary gland development. Proc. Nat1. Acad. Sci. 95: 5076-5081.

Cadigan, K. and R. Nusse. 1997. Wnt signaling: A common theme in animal development. Genes \& Dev. 11: 3286-3305.

Daniel, C.W. and K.B. DeOme. 1965. Growth of mouse mammary glands in vivo after monolayer culture. Science 149: 634-636.

Daniel, C.W. and G.B. Silberstein. 1987. Developmental biology of the mammary gland. In The mammary gland (ed. M.C. Neville and C.W Daniel), pp. 3-36. Plenum Press, New York, NY.

Das, S., X. Wang, B. Paria, D. Damm, J. Abraham, M. Klagsbrun, G. Andrews, and S. Dey. 1994. Heparin-binding EGF-like growth factor gene is induced in the mouse uterus temporally by the blastocyst solely at the site of its apposition: A possible ligand for interaction with blastocyst EGF-receptor in implantation. Development 120: 1071-1083.

DeOme, K.B., L.J. Faulkin, Jr., H.A. Bern, and P.B. Blair. 1959. Development of mammary tumors from hyperplastic alveolar nodules transplanted into gland-free mammary fat pads of female C3H Mice. Cancer Res. 19: 511-520.

Friedrich, G. and P. Soriano. 1993. Insertional mutagenesis by retroviruses and promoter traps in embryonic stem cells. Methods Enzymol. 225: 681-701.

Gavin, B.J. and A.P. McMahon. 1992. Differential regulation of the Wnt gene family during pregnancy and lactation suggests a role in post- natal development of the mammary gland. Mol. Cell. Biol. 12: 24182423.

Humphreys, R., J. Lydon, B. O'Malley, and J. Rosen. 1997. Mammary gland development is mediated by both stromal and epithelial progesterone receptors. Mol. Endocrinol. 11: 801-811.

Kispert, A., S. Vainio, and A. McMahon. 1998. Wnt-4 is a mesenchymal signal for epithelial transformation of metanephric mesenchyme in the developing kidney. Development 125: 4225-4234.

Lee, F., T. Lane, A. Kuo, G. Shackleford, and P. Leder. 1995. Insertional mutagenesis identifies a member of the Wnt gene family as a candidate oncogene in the mammary epithelium of int-2/Fgf-3 transgenic mice. Proc. Natl. Acad. Sci. 92: 2268-2272.

Lubahn, D., J. Moyer, T. Golding, J. Couse, K. Korach, and O. Smithies. 1993. Alteration of reproductive function but not prenatal sexual development after insertional disruption of the mouse estrogen receptor gene. Proc. Natl. Acad. Sci. 90: 11162-11166.

Lydon, J., M.F. De, C. Funk, S. Mani, A. Hughes, C.J. Montgomery, G. Shyamala, O. Conneely, and B. O'Malley. 1995. Mice lacking progesterone receptor exhibit pleiotropic reproductive abnormalities. Genes \& Dev. 9: 2266-2278.

Mombaerts, P., J. Iacomini, R. Johnson, K. Herrup, S. Tonegawa, and V. Papaioannou. 1992. RAG-1-deficient mice have no mature B and T lymphocytes. Cell 68: 869-877.

Munsterberg, A., J. Kitajewski, D. Bumcrot, A. McMahon, and A. Lassar. 1995. Combinatorial signaling by Sonic hedgehog and Wnt family members induces myogenic bHLH gene expression in the somite. Genes \& Dev. 9: 2911-2922.

Nandi, S. 1958. Endocrine control of mammary-gland development in the C3H/He Crgl mouse. J. Natl. Cancer Inst. 21: 1039-1063.

Nusse, R. and H. Varmus. 1982. Many tumors induced by the mouse mammary tumor virus contain a provirus integrated in the same region of the host genome. Cell 31: 99-109.

Nusse, R. and H. Varmus. 1992. Wnt genes. Cell 69: p1073-1087.

Roelink, H., E. Wagenaar, d.S.S. Lopes, and R. Nusse. 1990. Wnt-3, a gene activated by proviral insertion in mouse mammary tumors, is homologous to int-1/Wnt-1 and is normally expressed in mouse embryos and adult brain. Proc. Nat1. Acad. Sci. 87: 4519-4523.

Said, T., O. Conneely, D. Medina, B. O'Malley, and J. Lydon. 1997. Progesterone, in addition to estrogen, induces cyclin D1 expression in the murine mammary epithelial cell, in vivo. Endocrinology 138: 3933-3939.

Schroeder, J. and D. Lee. 1998. Dynamic expression and activation of ERBB receptors in the developing mouse mammary gland. Cell Growth Differ. 9: 451-464.

Silberstein, G., H.K. Van, G. Shyamala, and C. Daniel. 1996. Progesterone receptors in the mouse mammary duct: Distribution and developmental regulation. Cell Growth Differ. 7: 945-952.

Stark, K., S. Vainio, G. Vassileva, and A. McMahon. 1994. Epithelial transformation of metanephric mesenchyme in the developing kidney regulated by Wnt-4. Nature 372: 679-683.

Tan, J., S.K. Dey, and S.K. Das. 1999. Differential uterine expression of estrogen and progesterone receptors correlates with uterine preparation for implantation and decidualization in the mouse. Endocrinology 140: 5310-5321.

Tsukamoto, A., R. Grosschedl, R. Guzman, T. Parslow, and H. Varmus. 1988. Expression of the int-1 gene in transgenic mice is associated with mammary gland hyperplasia and adenocarcinomas in male and female mice. Cell 55: 619-625

Weber-Hall, S.J., D.J. Phippard, C.C. Niemeyer, and T.C. Dale. 1994 Developmental and hormonal regulation of Wnt gene expression in the mouse mammary gland. Differentiation 57: 205-214. 


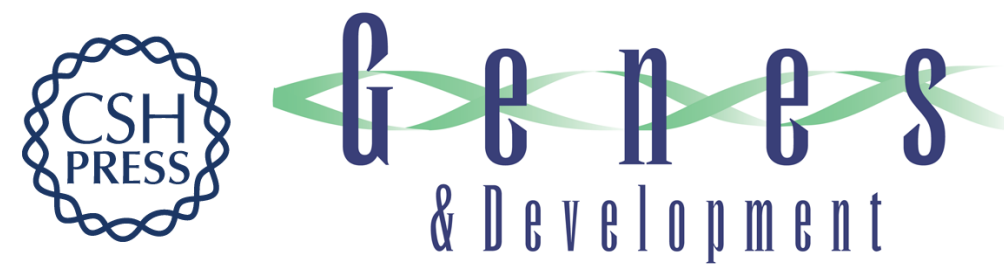

\section{Essential function of Wnt-4 in mammary gland development downstream of progesterone signaling}

Cathrin Brisken, Anna Heineman, Tony Chavarria, et al.

Genes Dev. 2000, 14:

Access the most recent version at doi:10.1101/gad.14.6.650

References This article cites 27 articles, 15 of which can be accessed free at: http://genesdev.cshlp.org/content/14/6/650.full.html\#ref-list-1

License

Email Alerting Receive free email alerts when new articles cite this article - sign up in the box at the top Service right corner of the article or click here.

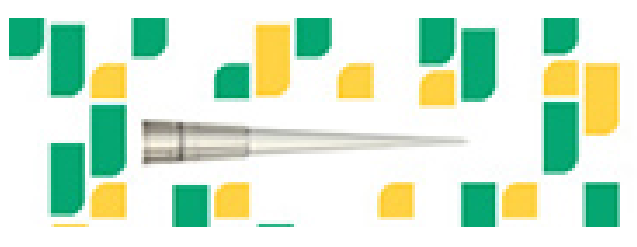

Focused on your science. 